\title{
Aspectos legais da produção de sementes e mudas de espécies florestais
}

\author{
Legal aspects of the production of seeds and seedlings of forest species \\ Aspectos legales de la producción de semillas y plántulas de especies forestales
}

Recebido: 18/01/2022 | Revisado: 28/01/2022 | Aceito: 19/02/2022 | Publicado: 28/02/2022

Edinaldo Cesar Tormes

ORCID: https://orcid.org/0000-0001-7390-3794 Universidade Federal de Pelotas, Brasil E-mail: edinaldotormes@apassul.com.br

Benhur Schwartz Barbosa

ORCID: https://orcid.org/0000-0002-8265-4598 Universidade de Federal de Pelotas, Brasil

E-mail: benhursb97@outlook.com

Henrique Berle

ORCID: https://orcid.org/0000-0002-4094-4642 Universidade de Federal de Pelotas, Brasil E-mail: henriqueberle@hotmail.com

Júlio Franscisco Uriarte

ORCID: https://orcid.org/0000-0002-6603-8007 Universidade de Federal de Pelotas, Brasil E-mail: jfuriarte@gmail.com

Henrique Ehlert Pollnow

ORCID: https://orcid.org/0000-0001-5156-4218 Universidade de Federal de Pelotas, Brasil E-mail: henriquepollnow.96@gmail.com

Mateus Pasa

ORCID: https://orcid.org/0000-0003-0481-0206 Universidade de Federal de Pelotas, Brasil E-mail: mateus.pasa@gmail.com

\begin{abstract}
Resumo
As espécies florestais de maior relevância no Brasil são o eucalipto (Eucalyptus grandis W. Hill ex Maide) e o pinus (Pinus elliottii Engelm). O presente estudo teve como objetivo revisar os aspectos legais para a produção, beneficiamento, armazenamento, comercialização e transporte de sementes e mudas de espécies florestais, para elucidar os principais pontos positivos e negativos da legislação. Mencionou, a Lei n ${ }^{\circ} 10.711,5$ de agosto de 2003. Na sequência, evidenciou o Decreto $\mathrm{N}^{\circ} 10.586$, de 18 de dezembro de 2020, que regulamenta a Lei $\mathrm{N}^{\circ} 10.711$, de 5 de agosto de 2003, que dispõe sobre o Sistema Nacional de Sementes e Mudas. Para as espécies florestais, as principais instruções normativas a serem consideradas são Instrução Normativa ${ }^{\circ}$ 17, de 26 de abril de 2017, Instrução Normativa $\mathrm{n}^{\circ} 19$, de 16 de maio de 2017, Instrução Normativa $\mathrm{n}^{\circ} 43$, de 15 de dezembro de 2015, Instrução Normativa $\mathrm{n}^{\mathrm{o}}$ 34, de 09 de setembro de 2014 e Instrução Normativa $\mathrm{n}^{\circ}$ 44, de 23 de dezembro de 2010. Para a produção de mudas, estabelece-se ainda a Instrução Normativa $n^{\circ} 24$, de 16 de dezembro de 2005 e Instrução Normativa $\mathrm{n}^{\circ} 42$ de 13 de outubro de 2009, para regulamentar a produção e comercialização de mudas de espécies florestais. As leis, decretos e instruções normativas referentes ao setor de sementes e mudas de espécies florestais são importantes ferramentas para auxiliar na manutenção da qualidade do produto final, porém é necessária atualização de algumas instruções normativas, decretos e leis, que envolvem o setor de sementes e mudas de espécies florestais, uma vez que há uma defasagem temporal das mesmas.
\end{abstract}

Palavras-chave: Eucalyptus grandis; Pinus elliotti; Instruções normativas.

\begin{abstract}
The most relevant forest species in Brazil are eucalyptus (Eucalyptus grandis W. Hill ex Maide) and pine (Pinus elliottii Engelm). The present study aimed to review the legal aspects for the production, processing, storage, commercialization and transport of seeds and seedlings of forest species, to elucidate the main positive and negative points of the legislation. He mentioned Law No. 10,711, of August 5, 2003. Subsequently, he highlighted Decree No. 10,586, of December 18, 2020, which regulates Law No. 10,711, of August 5, 2003, which provides for the System National Seeds and Seedlings. For forest species, the main normative instructions to be considered are Normative Instruction No. 17, of April 26, 2017, Normative Instruction No. 19, of May 16, 2017, Normative Instruction No. 43, of December 15, 2015, Instruction Normative No. 34, of September 9, 2014 and Normative Instruction No. 44, of December 23, 2010. For the production of seedlings, Normative Instruction No. 24, of December 16, 2005 and Normative Instruction No. 42 of October 13, 2009, to regulate the production and sale of seedlings of forest species. The laws, decrees and normative instructions referring to the sector of seeds and seedlings of forest species are important tools to help in the maintenance of the quality of the final product, however it is necessary to update some
\end{abstract}


normative instructions, decrees and laws, which involve the sector of seeds and seedlings of forest species, since there is a time lag.

Keywords: Eucalyptus grandis; Pinus elliottii; Normative instructions.

\section{Resumen}

Las especies forestales más relevantes en Brasil son el eucalipto (Eucalyptus grandis W. Hill ex Maide) y el pino (Pinus elliottii Engelm). El presente estudio tuvo como objetivo revisar los aspectos legales para la producción, procesamiento, almacenamiento, comercialización y transporte de semillas y plántulas de especies forestales, para dilucidar los principales puntos positivos y negativos de la legislación. Mencionó la Ley $\mathrm{N}^{\circ} 10.711$, de 5 de agosto de 2003. Posteriormente, destacó el Decreto $\mathrm{N}^{\circ}$ 10.586, de 18 de diciembre de 2020, que reglamenta la Ley $\mathrm{N}^{\circ} 10.711$, de 5 de agosto de 2003, que establece el Sistema Nacional de Semillas y Plantones. Para las especies forestales, las principales instrucciones normativas a considerar son la Instrucción Normativa $\mathrm{N}^{\circ} 17$, de 26 de abril de 2017 , la Instrucción Normativa $\mathrm{N}^{\circ} 19$, de 16 de mayo de 2017, la Instrucción Normativa $\mathrm{N}^{\circ}$ 43, de 15 de diciembre de 2015, la Instrucción Normativa $\mathrm{N}^{\circ}$ 34, de 9 de septiembre de 2014 e Instrucción Normativa $\mathrm{N}^{\circ}$ 44, de 23 de diciembre de 2010. Para la producción de plántulas, Instrucción Normativa $\mathrm{N}^{\circ} 24$, de 16 de diciembre de 2005 e Instrucción Normativa $\mathrm{N}^{\circ} 42$ de 13 de octubre de 2009, para regular la producción y venta de plántulas de especies forestales. Las leyes, decretos e instructivos normativos referentes al sector de semillas y plántulas de especies forestales son herramientas importantes para auxiliar en el mantenimiento de la calidad del producto final, sin embargo es necesario actualizar algunas instructivos normativos, decretos y leyes, que involucran las semillas y plántulas de especies forestales, ya que existe un desfase temporal.

Palabras clave: Eucalyptus grandis; Pinus elliottii; Instrucciones normativas.

\section{Introdução}

O setor brasileiro de arvores plantadas impulsiona a economia nacional com um Produto Interno Bruto (PIB) setorial de $\mathrm{R} \$ 86,6$ bilhões, representando 1,3\% do PIB brasileiro e 6,9\% do PIB industrial (Indústria Brasileira de Árvores [IBA], 2019). As espécies florestais de maiores relevâncias no Brasil são o eucalipto (Eucalyptus spp) e o pinus (Pinus spp), sendo que o Brasil tem uma ampla lista de espécies madeireiras beneficiadas e comercializadas, em torno de 157 catalogadas pelo Laboratório de Produtos Florestais do Serviço Florestal Brasileiro (Sistema Nacional de Informações Florestais [SNIF], 2020).

O Brasil lidera o ranking global de produtividade florestal, com uma média de $35,7 \mathrm{~m}^{3} / \mathrm{ha} / \mathrm{ano}$ para os plantios de eucalipto e $30,5 \mathrm{~m}^{3} / \mathrm{ha} / \mathrm{ano}$ nos plantios de pinus. Esses valores são quase duas vezes maiores do que a produtividade das florestas em países do hemisfério norte. Apesar de ocupar uma pequena parcela do território nacional (aproximadamente 1\% da área do país), o setor é responsável por $91 \%$ de toda a madeira produzida para fins industriais no país (Ministério da Agricultura, Pecuária e Abastecimento [MAPA], 2018).

No Brasil existem cerca de 7.880 espécies arbóreas, sendo que mais de 4 mil delas estão presentes no Catálogo de Árvores do Brasil, elaborado pelo Laboratório de Produtos Florestais do Serviço Florestal Brasileiro. Este catálogo contém cerca de 15 mil nomes comuns e comerciais relacionados aos nomes científicos das respectivas espécies, no catálogo são encontradas espécies que ocorrem em todos os biomas brasileiros (SNIF, 2020).

Com uma área total de árvores plantadas no Brasil de 7,83 milhões de hectares, o setor impacta 1.000 munícipios em 23 Estados. A geração de empregos diretos em 2018 foi de 513 mil trabalhadores, impactando 3,8 milhões pessoas direta e indiretamente. As exportações em 2018, com vendas de US\$ 12,5 bilhões, aumentaram 24,1\% em comparação ao ano de 2017. A celulose teve desempenho recorde no mercado externo, com o Brasil sendo destaque no comércio mundial como o maior exportador desse insumo (IBA, 2019).

As perspectivas futuras indicam que haverá uma evolução da multiplicação das plantas através de diversos mecanismos de propagação, neste cenário, a multiplicação de plantas por sementes permite que determinada característica fenotípica de interesse possa vir a ser herdada para a próxima geração, e que a variabilidade genética também esteja presente, para que, desta forma, haja a possibilidade de que a característica de interesse possa vir a ser introduzida nas novas gerações, diante destes fatos, fica ao encargo das técnicas de melhoramento genético estabelecerem métodos que viabilizem a manifestação destas características de interesse (Hoppe et al., 2004). 
Referindo-se aos aspectos legais de produção de sementes de espécies florestais, foram criados Códigos, Leis, Decretos e Instruções Normativas que regulam e incentivam a preservação e a utilização dos recursos brasileiros de maneira sustentável. Apesar disto, a morosidade das fiscalizações, de estudos e, principalmente, de dispositivos que proporcionem a certificação do comércio de sementes e mudas, fazem com que esses recursos legislativos nem sempre sejam efetivados, a informalidade causa uma serie de prejuízos ao setor de sementes e mudas, uma vez que, a comercialização de sementes não certificadas, por exemplo, aumenta a ocorrência de plantas daninhas, bem como pragas e doenças, além de que, no caso das sementes, elas podem apresentar baixa germinação e vigor, todos estes fatores mencionados acabam afetando negativamente na produção das espécies vegetais (Oliveira et al., 2014).

Diante do exposto, o presente estudo teve como objetivo revisar aspectos legais para a produção, beneficiamento, armazenamento, comercialização e transporte de sementes e mudas de espécies florestais, para elucidar os principais pontos positivos e negativos da legislação.

\section{Metodologia}

Uma revisão bibliográfica é considerada um trabalho onde o autor realiza pesquisa, leitura e análise de estudos já publicados na literatura que apresentem temáticas semelhantes ao conteúdo a ser abordado, possibilitando, desta forma, realizar uma discussão dos resultados encontrados, e consequentemente formular conclusões relacionadas ao objetivo do estudo (Pereira et al., 2018). Nesse contexto, o presente estudo foi realizado adotando o método de revisão bibliográfica.

Com o intuito de atingir os objetivos propostos pelo trabalho foram realizadas buscas nas plataformas de pesquisa SciELO, Google Acadêmico e Periódicos Capes, por apresentarem um vasto portfólio de trabalhos, que foram suficientes para a elaboração do presente estudo. Ainda, para complementar a pesquisa, também foram acessados portais de órgãos governamentais, tais como, Palácio do Planalto e Ibama. Sendo que os estudos foram localizados mediante uma busca avançada, com as seguintes palavras chaves: Eucalyptus grandis, Pinus elliottii, instruções normativas para a produção, beneficiamento, armazenamento, comercialização e transporte de sementes e mudas de espécies florestais. Por outro lado, foram excluídos artigos que não apresentavam temáticas semelhantes deste estudo.

Com isso, para contemplar este estudo foram realizadas leituras de artigos científicos divulgados por revistas cientificas e documentos expedidos por órgão governamentais sobre a temática proposta para o presente trabalho. Através das filtragens mencionadas anteriormente, esta pesquisa foi embasada na leitura de 17 publicações, podendo elas serem divididas em três diferentes eixos temáticos (Quadro 1).

Quadro 1: Referências distribuídos pelos seus respectivos eixos temáticos.

\begin{tabular}{|l|l|}
\hline Eixos Temáticos & Referências \\
\hline Decretos e Leis & $\begin{array}{l}\text { Decreto } N^{\circ} \text { 10.586, de 18 de dezembro de 2020. (2020). Regulamenta a Lei No 10.711, de 5 de agosto de } \\
\text { 2003. Recuperado em: https://www.in.gov.br/en/web/dou/-/decreto-n-10.586-de-18-de-dezembro-de-2020- } \\
\text { 295257581; Lei } n^{\circ} \text { 10.711, 5 de agosto de 2003. (2003). Dispõe sobre o Sistema Nacional de Sementes e } \\
\text { Mudas e dá outras providências. http://www.planalto.gov.br/ccivil_03/leis/2003/110.711.htm. }\end{array}$ \\
\hline $\begin{array}{l}\text { Conceitos teóricos sobre } \\
\text { sementes florestais }\end{array}$ & $\begin{array}{l}\text { Brasil. Regras para análise de sementes. Secretaria de Defesa Agropecuária. Brasília: MAPA/ACS, 2009. 395 } \\
\text { p.; Hoppe, J. M., \& Brun, E. J. (2004). Produção de sementes e mudas florestais. Caderno didático, 1(2); IBA. } \\
\text { Indústria Brasileira de Arvores. (2019). Relatório 2019. https://iba.org/datafiles/publicacoes/relatorios/iba- } \\
\text { relatorioanual2019.pdf; MAPA, Ministério da Agricultura, Pecuária e Abastecimento. (2013). Instruçóes para } \\
\text { análise de sementes de espécies florestais. https://www.gov.br/agricultura/pt- } \\
\text { br/assuntos/laboratorios/arquivos-publicacoes-laboratorio/florestal_documento_pdf-ilovepdf-compressed.pdf; } \\
\text { MAPA. Ministério da Agricultura, Pecuária e Abastecimentos. (2018). Plano Nacional de Desenvolvimento } \\
\text { de Florestas Plantadas. Recuperado em: https://www.gov.br/agricultura/pt-br/assuntos/politica- } \\
\text { agricola/outras-publicacoes/plano-nacional-de-desenvolvimento-de-florestas-plantadas.pdf; Oliveira, J. P. R., } \\
\text { \& Ranal, M. A. (2014). Sementes florestais brasileiras: início precário, presente inebriante e o futuro, } \\
\text { promissor?. Ciência Florestal, 24(3), 771-784. https://doi.org/10.1590/1980-509820142403024; SNIF. } \\
\text { Sistema Nacional de Informações Florestais. (2020). Espécies Florestais. https://snif.florestal.gov.br/pt- }\end{array}$ \\
\hline
\end{tabular}




\begin{tabular}{|c|c|}
\hline & br/especies-florestais \\
\hline Instruções Normativas & 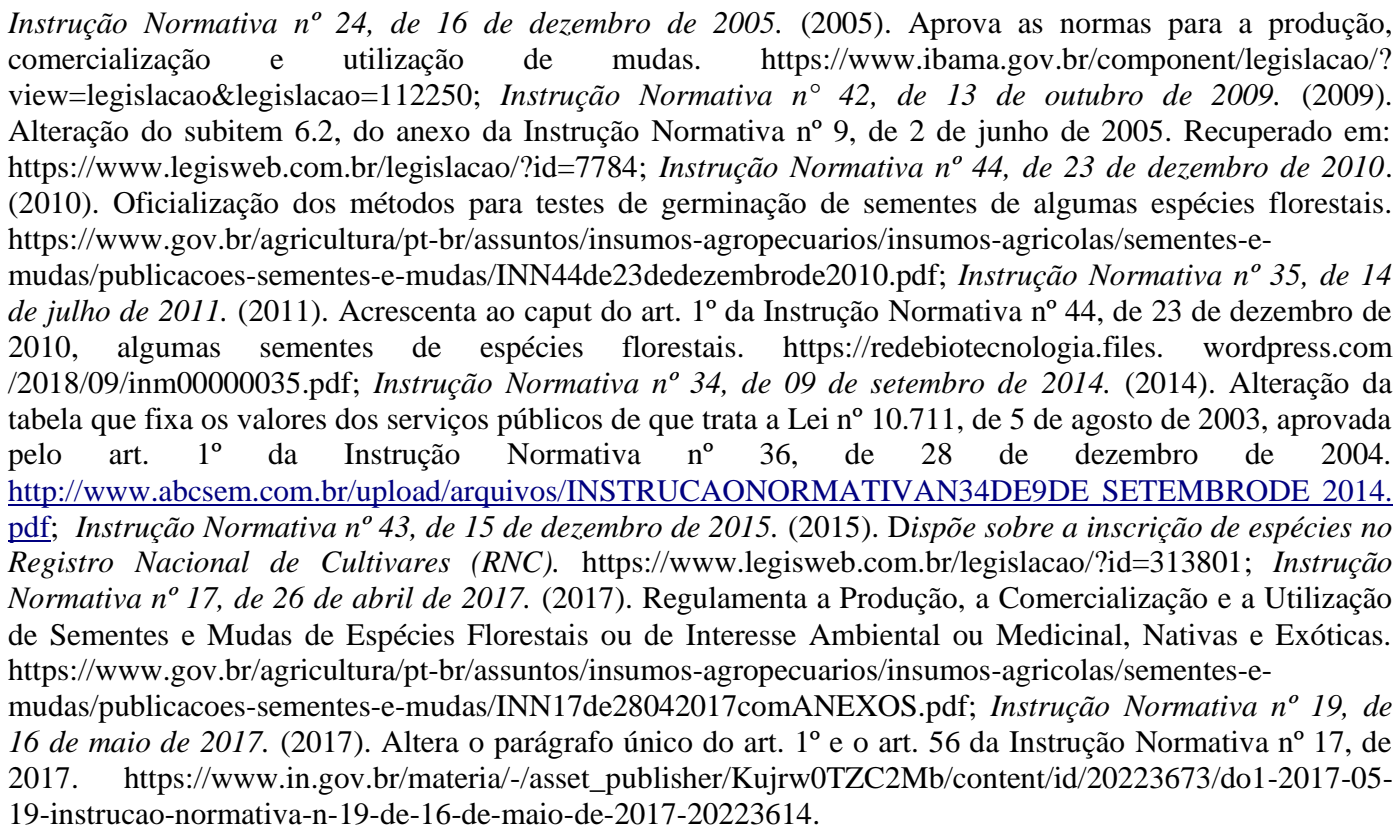 \\
\hline
\end{tabular}

Fonte: Autores.

\section{Resultados e Discussão}

\section{Enquadramento das Bases legais para produção de sementes e mudas de espécies florestais}

Há basicamente uma lei e um decreto que são utilizadas como bases legais para a produção de sementes e mudas de espécies florestais, estas serão mencionadas posteriormente no presente trabalho para uma melhor compreensão, bem como para as instruções normativas referentes à produção de sementes e mudas, de forma específica para cada uma, de espécies florestais. A lei $n^{o}$ 10.711, 5 de agosto de 2003, que dispõe sobre o Sistema Nacional de Sementes e Mudas e dá outras providências Lei n. 10.711 (2003). E o decreto $\mathrm{N}^{\circ} 10.586$, de 18 de dezembro de 2020, que regulamenta a Lei $\mathrm{N}^{\circ} 10.711$, de 5 de agosto de 2003, que dispõe sobre o Sistema Nacional de Sementes e Mudas Decreto, sendo que este revogou o Decreto $\mathrm{n}^{\circ}$ 5.153, de 23 de julho de 2004 Decreto n. 10.586 (2020).

A seguir serão abordadas as principais instruções normativas referentes à produção de sementes de espécies florestais e posteriormente para a produção de mudas.

\section{Sementes}

A Instrução Normativa $n^{o}$ 44, de 23 de dezembro de 2010, oficializa os métodos para testes de germinação de sementes de algumas espécies florestais, tais como, Acacia polyphylla, Albizia hassleri, Anadenanthera colubrina, Anadenanthera macrocarpa, Apuleia leiocarpa, Astronium fraxinifolium, Cariniana estrellensis, Cariniana legalis, Cassia leptophylla, Cedrela fissilis, Cedrela odorata, Ceiba speciosa, Copaifera langsdorffii, Cordia americana, Cybistax antisyphilitica, Cytharexylum myrianthum, Dalbergia miscolobium, Dalbergia nigra, Enterolobium contortisiliquum, Enterolobium maximum, Erythrina speciosa, Gallesia integrifolia, Guazuma ulmifolia, Hymenaea courbaril, Hymenaea stigonocarpa, Jacaranda cuspidifolia, Jacaranda micrantha, Lafoensia pacari, Mimosa caesalpiniaefolia, Mimosa scabrella, Ormosia arborea, Parapiptadenia rigida, Parkia pendula, Peltogyne confertiflora, Peltophorum dubium, Platymenia reticulata, Pseudobombax tomentosum, Pterogyne nitens, Qualea grandiflora, Schinus terebinthifolius, Schizolobium parahyba var. amazonicum, Senna macranthera, Senna multijuga, Stryphnodendron barbadetiman, Stryphnodendron 
polyphyllum, Tabebuia aurea, Tabebuia chrysotricha, Tabebuia impetiginosa, Tabebuia roseo-alba e Zeyheria tuberculosa Instrução Normativa n.44 (2010).

A Instrução Normativa $n^{\circ}$ 35, de 14 de julho de 2011, que acaba sendo uma revisão da metodologia mencionada anteriormente, acrescenta ao caput do art. $1^{\circ}$ da Instrução Normativa $n^{\circ}$ 44, de 23 de dezembro de 2010, as sementes de Acacia polyphylla, Cariniana estrellensis, Cedrela fissilis, Cedrela odorata, Cytharexylum myrianthum, Jacaranda cuspidifolia, Jacaranda micrantha, Ormosia arborea, Parapiptadenia rigida, Parkia pendula, Platymenia reticulata, Schizolobium parahyba var. amazonicum, Senna macranthera, Tabebuia chrysotricha e Tabebuia roseo-alba Instrução Normativa n.35 (2011).

A Instrução Normativa $n^{\circ}$ 34, de 09 de setembro de 2014 foi criada com o intuito de alterar a tabela que fixa os valores dos serviços públicos de que trata a Lei $\mathrm{n}^{\circ} 10.711$, de 5 de agosto de 2003 , aprovada pelo art. $1^{\circ}$ da Instrução Normativa n ${ }^{\circ}$ 36, de 28 de dezembro de 2004 Instrução Normativa n.34 (2014).

A Instrução Normativa $n^{\circ}$ 43, de 15 de dezembro de 2015 dispõe sobre a inscrição de espécies no Registro Nacional de Cultivares (RNC) na Coordenação de Sementes e Mudas (CSM), do Departamento de Fiscalização de Insumos Agrícola (DFIA), da Secretaria de Defesa Agropecuária (DAS), e do Ministério da Agricultura, Pecuária e Abastecimento (MAPA) Instrução Normativa n.43 (2015).

A Instrução Normativa n ${ }^{\circ}$ 17, de 26 de abril de 2017 regulamenta a produção, a comercialização e a utilização de sementes e mudas de espécies florestais ou de interesse ambiental ou medicinal, nativas e exóticas, visando garantir sua procedência, identidade e qualidade, além de que ela revogou a Instrução Normativa $n^{\circ} 56$, de 8 de dezembro de 2011 Instrução Normativa n.17 (2017).

Um documento publicado pelo MAPA, intitulado como instruções para análises de sementes de espécies florestais, tem o objetivo de estabelecer procedimentos para amostragem, análise de pureza e teste de germinação de espécies não comtempladas na RAS - Regras de análise de Sementes (MAPA, 2013). Tanto que na RAS há a informação de que das 319 espécies que as metodologias de análise foram descritas pelo documento, a maioria carece de validação do método, por isso ainda não foram oficializadas, devendo ser utilizadas apenas como referência (Brasil, 2009).

\section{Mudas}

Há duas instruções normativas que servem de base para a produção de mudas de espécies florestais. A Instrução Normativa $n^{\circ} 24$, de 16 de dezembro de 2005, que estabelece normas para a produção, comercialização e utilização de mudas Instrução Normativa n.24 (2005). E a Instrução Normativa ${ }^{\circ}$ 42, de 13 de outubro de 2009, onde no Art. $1^{\circ}$ altera o subitem 6.2, do anexo da Instrução Normativa $n^{\circ}$ 9, de 2 de junho de 2005 Instrução Normativa n.42 (2009).

Há pontos positivos e negativos a serem considerados nas instruções normativas citadas anteriormente. De forma geral, a defasagem temporal em relação à oficialização dos métodos para os testes de germinação de sementes das espécies florestais é um ponto negativo, com isso, se torna necessária à atualização das instruções normativas, bem como a necessidade de acrescentar metodologias para outras espécies florestais que não estão inseridas nas instruções normativas atualmente. Neste mesmo sentido, as instruções normativas para a produção de mudas de espécies florestais também necessitam de atualizações, visto que fazem mais de uma década que elas foram estabelecidas. Por outro lado, a regulamentação da produção, comercialização e utilização de sementes e mudas de espécies florestais é um fator positivo, uma vez que estas atribuições aumentam a garantia da qualidade do produto final (sementes e mudas), evidente que para que isso ocorra estas atribuições devem ser seguidas da melhor forma possível, porém em muitos casos isso não acontece. 


\section{Competências do MAPA}

De acordo com a Lei $n^{\circ} 10.711,5$ de agosto de 2003, as seguintes competências, relacionadas a produção de sementes e mudas de espécies florestais, são atribuídas ao MAPA Lei n.10.711 (2003):

Art. $1^{\circ}$. O Sistema Nacional de Sementes e Mudas, instituído nos termos desta lei e de seu regulamento, objetiva garantir a identidade e a qualidade do material de multiplicação e de reprodução vegetal produzido, comercializado e utilizado em todo o território nacional.

Art. $4^{\circ}$. Compete ao MAPA promover, coordenar, normatizar, supervisionar, auditar e fiscalizar as ações decorrentes desta lei e de seu regulamento.

Art. 47. Fica o Mapa autorizado a estabelecer mecanismos específicos e, no que couber, exceções ao disposto nesta lei, para regulamentação da produção e do comércio de sementes de espécies florestais, nativas ou exóticas, ou de interesse medicinal ou ambiental, bem como para as demais espécies referidas no parágrafo único do art. 24.

\section{Aspectos legais para produção de sementes de espécies florestas}

A seguir serão relatados alguns artigos, parágrafos e incisos, da instrução normativa $\mathrm{n}^{\circ} 17$, de 26 de abril de 2017 , sendo estes referentes aos aspectos legais para a produção de sementes de espécies florestais Instrução Normativa n.17 (2017).

Art. $1^{\circ}$ Regulamentar a Produção, a Comercialização e a Utilização de Sementes e Mudas de Espécies Florestais ou de Interesse Ambiental ou Medicinal, Nativas e Exóticas, visando garantir sua procedência, identidade e qualidade.

Parágrafo único. Dispensa-se das exigências desta instrução normativa aqueles que produzem exclusivamente em sua propriedade ou de que detenha a posse, e que comercializam diretamente ao usuário, até 10.000 mudas por ano de espécies nativas, Florestais ou de Interesse Ambiental ou Medicinal. (Redação dada pela Instrução Normativa MAPA nº 19 , de 16 de maio de 2017).

Art. $6^{\circ} \mathrm{O}$ produtor de sementes ou o produtor de mudas, que coleta as próprias sementes para o uso em sua produção de mudas, deverá inscrever a produção por meio da declaração da fonte de sementes para cada espécie e cultivar, que pretenda produzir, ao órgão de fiscalização da Unidade da Federação, onde a fonte de sementes esteja instalada, até 30 (trinta) de março do ano corrente.

$\S 4^{\circ} \mathrm{O}$ produtor inscrito no RENASEM, sem prejuízo da penalidade de multa sobre o total de sementes produzidas, comercializadas ou não, poderá regularizar a inscrição ou a declaração da fonte de sementes fora dos prazos estabelecidos, desde que:

I - Apresente a documentação exigida ao órgão de fiscalização para a inscrição da produção; e

II - O responsável técnico apresente um laudo de vistoria descrevendo o processo de obtenção das sementes, quando estas forem das categorias selecionadas, qualificadas ou testadas.

Lembrando que uma das premissas da Instrução Normativa mencionada anteriormente é de oportunizar ao produtor de sementes ou de mudas a regularização de sua produção, quando possível, e desta forma, aproveitar comercialmente o material produzido, no entanto, o produtor deverá estrar inscrito no Registro Nacional de Sementes e Mudas (RENASEM) Instrução Normativa n.17 (2017).

Em relação ao transporte de sementes de espécies vegetais o Art. 12 diz que as sementes ou os frutos, contendo as sementes, deverão estar acompanhados da nota fiscal, ou do laudo de vistoria ou do contrato de prestação de serviço do coletor, quando estiverem sendo transportados para beneficiamento ou armazenamento fora da propriedade onde se realizou a coleta dos frutos ou das sementes. Enquanto que o Art. 34 diz respeito à identificação do material, evidenciando que as sementes deverão estar identificadas desde a coleta até sua comercialização Instrução Normativa n.17 (2017).

O Art. 35 estabelece normas para a identificação após a coleta, onde o material coletado deverá estar identificado com, no mínimo, as seguintes informações Instrução Normativa n.17 (2017): 
I - nome da espécie e da cultivar, quando for o caso;

II - nome do município onde as sementes foram coletadas, conforme a declaração de fonte de sementes;

III - categoria;

IV - data da coleta; e

$\mathrm{V}$ - nome do produtor.

Já o Art. 36 é referente à identificação para comercialização, para tal, as sementes deverão estar identificadas diretamente na embalagem ou mediante rótulo, etiqueta ou carimbo, com, no mínimo, as seguintes informações Instrução Normativa n.17 (2017):

I - nome científico da espécie e do nome comum, obedecida a denominação constante no Registro Nacional de Cultivares - RNC;

II - nome da cultivar, quando for o caso, obedecida a denominação constante no RNC; III - nome e número da inscrição do produtor no RENASEM;

IV - categoria da semente; V - identificação do lote;

VI - período da coleta (mês/ano);

VII - peso líquido ou número de sementes contido na embalagem;

VIII - percentagem de geminação ou viabilidade do lote de sementes;

IX - validade do teste de germinação ou viabilidade do lote de sementes;

$\mathrm{X}$ - nome dos municípios onde as sementes do lote foram coletadas, conforme a declaração de fonte de sementes;

XI - número do Termo de Conformidade de Semente Florestal; e

XII - a expressão “A cópia do Termo de Conformidade de Semente Florestal poderá ser solicitada ao produtor”.

Há, em geral, duas regras para a realização da identificação das espécies florestais. A primeira esta relacionada com as espécies que possuem métodos estabelecidos pela Instrução Normativa n.44 de 2010 e pela Instrução Normativa n.35 de 2011 , neste caso, devem conter obrigatoriamente no rótulo, etiqueta ou carimbo das sementes comercializadas os dados de percentagem de germinação e validade do teste de germinação, ou, viabilidade do lote de sementes. A segunda regra engloba as espécies que não possuem método de análise estabelecido e oficializado, nesta situação, deveram apresentar a informação de percentagem de geminação ou viabilidade da semente, destacando que "Não há metodologia oficializada pelo MAPA disponível para a espécie", essas informações deverão constar no termo de conformidade Instrução Normativa n.17 2017).

Para a comercialização e transporte de sementes de espécies florestais, de acordo com o Art. 56 da Instrução Normativa $\mathrm{n}^{\circ}$ 19, de 16 de maio de 2017 é permitido o comércio ambulante de mudas de espécies florestais ou de interesse ambiental ou medicinal, desde que atendidas todas as exigências desta norma. Enquanto que o Art. 57 indica que na comercialização e no transporte, a semente, o material de propagação vegetativa e a muda deverão estar acompanhados da respectiva nota fiscal:

$\S 1^{\circ}$ O Termo de Conformidade de Semente Florestal, ou o Termo de Conformidade de Material de Propagação Vegetativa, ou o Termo de Conformidade de Muda Florestal, conforme o caso, ficará à disposição do comprador ou da fiscalização junto ao produtor.

$\S 2^{\circ}$ A cópia do Termo de Conformidade de Semente Florestal, ou do Termo de Conformidade de Material de Propagação Vegetativa, ou do Termo de Conformidade de Muda Florestal, quando solicitada pelo comprador, deverá ser entregue juntamente com a nota fiscal ou disponibilizada por meio eletrônico ou impresso no prazo de 5 (cinco) dias úteis.

Alguns dados são obrigatórios estarem contidos na nota fiscal de sementes de espécies florestais, sendo assim, o Art. 58 da Instrução Normativa n. 17 (2017), a nota fiscal de venda deverá conter, no mínimo, as seguintes informações:

I - número da inscrição no RENASEM do produtor ou do reembalador do material de propagação comercializado;

II - nome, inscrição no CPF ou no CNPJ e endereço do comprador; 
III - especificação da quantidade de cada lote de semente, de material de propagação vegetativa ou de muda, por espécie e cultivar, quando for o caso;

IV - identificação dos respectivos lotes; e

V - número do Termo de Conformidade dos lotes comercializados.

As atribuições e regras estabelecidas para a produção beneficiamento, armazenamento, comercialização e transporte de sementes de espécies florestais, que foram explanadas anteriormente, proporcionam uma maior qualidade no setor de sementes florestais, entretanto, se torna necessário avanços nestas regras e atribuições, para que assim seja possível trazer melhorias para este setor, e isso somente será possível de ocorrer através de avançados estudos que proporcionem resultados que possam trazer conclusões de quais aspectos devem ser melhorados.

\section{Aspectos legais para a produção de mudas de espécies florestais}

Para a produção de mudas de espécies florestais, além da Lei e do Decreto, devem ser consideradas, a Instrução Normativa $\mathrm{n}^{\circ}$ 24, de 16 de dezembro de 2005, a Instrução Normativa ${ }^{\circ}$ 9, de 02 de junho de 2005 e a Instrução Normativa ${ }^{\circ}$ 42, de 13 de outubro de 2009. Estas serão descritas posteriormente no presente trabalho.

Instrução Normativa ${ }^{\circ} 24$, de 16 de dezembro de 2005 :

Ela aprova as normas para produção, comercialização e utilização de mudas, tendo por objetivo fixar diretrizes básicas a serem obedecidas na produção, comercialização e utilização de mudas, em todo o território nacional, visando à garantia de sua identidade e qualidade. Esta Instrução Normativa estabelece que o interessado em produzir mudas deverá inscrever-se no RENASEM. Além disso, ela descreve procedimentos para a inscrição das plantas fornecedoras de material de propagação, tais como, planta básica, planta matriz, jardim clonal e borbulheira.

O sistema de produção de mudas, organizado na forma destas normas, incluindo o processo de certificação, tem por objetivo disponibilizar material de propagação vegetal com garantia de identidade e qualidade, atendidos os padrões e as normas específicas estabelecidas. O processo de certificação contemplará as categorias de planta básica, planta matriz e muda certificada:

A muda certificada poderá ser obtida:

I - a partir de material de propagação proveniente de:

a) planta básica;

b) planta matriz;

c) jardim clonal ou;

d) borbulheira.

II - a partir de sementes, das categorias:

a) genética;

b) básica;

c) certificada de primeira geração - $\mathrm{C} 1$;

ou d) certificada de segunda geração - C2.

A muda não certificada poderá ser obtida:

I - a partir de material de propagação proveniente de:
a) planta básica;
b) planta matriz;
c) jardim clonal;
d) borbulheira; 
e) muda certificada;

f) borbulheira ou jardim clonal não submetidos ao processo de certificação ou;

g) plantas ou campo de plantas fornecedoras de material de propagação sem origem genética comprovada.

II - a partir de sementes, das categorias:

a) genética;

b) básica;

c) certificada de primeira geração - $\mathrm{C} 1$;

d) certificada de segunda geração - C2;

e) sementes S1 ou;

f) sementes $S 2$.

Segundo a Instrução Normativa n.24 (2005) a certificação é o processo que, obedecidos normas e padrões específicos, objetiva a produção de mudas, mediante controle de qualidade em todas as suas etapas, incluindo o conhecimento da origem genética e o controle de gerações. A certificação da produção será realizada pelo MAPA, pela entidade certificadora ou certificador de produção própria, credenciados no RENASEM.

Instrução Normativa ${ }^{\circ} 42$ de 13 de outubro de 2009:

No Art. $1^{\circ}$ esta Instrução Normativa alterar o subitem 6.2, do Anexo da Instrução Normativa $n^{\circ} 9$, de 2 de junho de 2005, que passa a vigorar com a seguinte redação:

6.2. O campo para produção de sementes deverá ser inscrito no órgão de fiscalização da Unidade da Federação onde este esteja instalado, sendo que, no caso em que a inscrição de campo de produção de sementes for realizada em Unidade da Federação distinta daquela onde o produtor esteja inscrito no RENASEM, o órgão de fiscalização depositário da inscrição disponibilizará ao órgão de fiscalização da unidade da federação onde o produtor esteja inscrito no RENASEM, no prazo máximo de cinco dias, contados da homologação da inscrição, cópia da relação de campos de produção de sementes.

Já o Art. $2^{\circ}$ alterar os subitens 6.1.1, 6.2.1, 6.2.3 e 7.2, do Anexo da Instrução Normativa nº 24 , de 16 de dezembro de 2005, que passam a vigorar com as seguintes redações:

6.1.1. A inscrição da Planta Básica, da Planta Matriz, do Jardim Clonal ou da Borbulheira deverá ser solicitada ao órgão de fiscalização da Unidade da Federação em que estes estejam instalados, e ser renovada a cada três anos, salvo o previsto em normas específicas.

6.2.1. A inscrição de planta fornecedora de material de propagação sem origem genética comprovada deverá ser solicitada ao órgão de físcalização da Unidade da Federação, onde esta esteja instalada, e renovada, salvo o previsto em normas específicas, a cada três anos.

6.2.3. O campo de plantas oriundo da planta fornecedora de material de propagação sem origem genética comprovada, desde que tenha o objetivo de fornecer material de propagação, deverá ser inscrito no órgão de fiscalização onde este esteja instalado, ficando neste caso sujeito à apresentação da documentação estabelecida nos incisos I, III, IV, V e VI do subitem 6.2.2 e Termo de Conformidade do material de propagação, e a inscrição deverá ser renovada, salvo o previsto em normas específicas, a cada três anos.

7.2. O produtor de mudas deverá solicitar a inscrição do viveiro ou da unidade de propagação in vitro ao órgão de fiscalização da Unidade da Federação, no qual o viveiro ou a unidade de propagação in vitro esteja instalado.

Enquanto que o Art. $3^{\circ}$ acrescenta os subitens 6.10 e 7.14, no Anexo da Instrução Normativa ${ }^{\circ} 24$, de 16 de dezembro de 2005, com as seguintes redações:

6.10. O órgão de fiscalização, onde foram efetuadas as inscrições previstas nos subitens 6.1.1, 6.2.1 e 6.2.3, deverá enviar cópia dos certificados de inscrição, no prazo de 05 (cinco) dias da emissão destes certificados, ao órgão de fiscalização onde o produtor estiver inscrito no RENASEM. 
7.14. O órgão de fiscalização, onde foi efetuada a inscrição prevista no subitem 7.2, deverá enviar cópia da caracterização do viveiro ou unidade de propagação in vitro homologada, no prazo de 05 (cinco) dias da homologação, ao órgão de fiscalização onde o produtor estiver inscrito no RENASEM.

Todos os itens que foram mencionados anteriormente, relacionados aos aspectos legais para a produção de mudas de espécies florestais, trazem maior segurança, confiabilidade e qualidade quanto ao produto final. Entretanto a defasagem temporal da legislação vigente para a produção de mudas de espécies florestais é algo que deve ser melhorado, pois com o passar dos anos, novas pesquisas se tornam necessárias para melhorar este setor, e com isso, os resultados obtidos nesses trabalhos devem ser utilizados como base para a criação de novas leis, decretos e instruções normativas relacionadas aos aspectos legais para a produção de mudas de espécies florestais, para que, desta forma, este setor possa ter novos avanços.

\section{Responsabilidade técnica}

Segundo o Art. 47, da Lei n ${ }^{\circ} 10.711$, de 2003, no caso de produção de sementes, de material de propagação vegetativa e de mudas das espécies florestais ou de interesse ambiental ou medicinal, o responsável técnico deverá ser profissional qualificado e devidamente registrado no respectivo conselho profissional, que o habilite para:

I - orientar a seleção fenotípica ou genética de matrizes nas fontes de sementes, quando couber; e

II - recomendar técnicas silviculturais, procedimentos de preparo de solo e de plantio, de correção de solo e adubação, de irrigação e drenagem, de controle fitossanitário de pragas, de beneficiamento, de armazenamento, de tecnologia de sementes, de manejo das mudas no viveiro e da produção do material de propagação vegetativa e de manejo a serem adotados na fonte de sementes.

\section{Conclusão}

O setor de produção de sementes de espécies florestais se concentra em duas espécies (Eucalipto e Pinus), no entanto apresenta mais de 7 mil espécies.

As leis, decretos e instruções normativas referentes ao setor de sementes e mudas de espécies florestais são importantes ferramentas para auxiliar na manutenção da qualidade do produto final.

É necessária atualização de algumas instruções normativas, decretos e leis, que envolvem o setor de sementes e mudas de espécies florestais, uma vez que há uma defasagem temporal das mesmas.

Diante das conclusões obtidas neste trabalho, recomenda-se para pesquisas futuras a realização de trabalhos com sementes e mudas de espécies florestais com temáticas que possam vir a contribuir para a confecção de uma legislação mais atualizada e robusta.

\section{Referências}

Brasil. Regras para análise de sementes. Secretaria de Defesa Agropecuária. Brasília: MAPA/ACS, 2009. 395 p.

Decreto $N^{\circ}$ 10.586, de 18 de dezembro de 2020. (2020). Regulamenta a Lei $\mathrm{N}^{\circ} 10.711$, de 5 de agosto de 2003 . Recuperado em: https://www.in.gov.br/en/web/dou/-/decreto-n-10.586-de-18-de-dezembro-de-2020-295257581

Hoppe, J. M., \& Brun, E. J. (2004). Produção de sementes e mudas florestais. Caderno didático, 1(2).

IBA. Indústria Brasileira de Arvores. (2019). Relatório 2019. https://iba.org/datafiles/publicacoes/relatorios/iba-relatorioanual2019.pdf

Instrução Normativa $n^{o}$ 24, de 16 de dezembro de 2005. (2005). Aprova as normas para a produção, comercialização e utilização de mudas. https://www.ibama.gov.br/component/legislacao/?view=legislacao\&legislacao $=112250$

Instrução Normativa $n^{\circ} 42$, de 13 de outubro de 2009. (2009). Alteração do subitem 6.2, do anexo da Instrução Normativa $\mathrm{n}^{\circ} 9$, de 2 de junho de 2005. Recuperado em: https://www.legisweb.com.br/legislacao/?id=77843 
Research, Society and Development, v. 11, n. 3, e37911325903, 2022

(CC BY 4.0) | ISSN 2525-3409 | DOI: http://dx.doi.org/10.33448/rsd-v11i3.25903

Instrução Normativa $n^{o}$ 44, de 23 de dezembro de 2010. (2010). Oficialização dos métodos para testes de germinação de sementes de algumas espécies florestais. https://www.gov.br/agricultura/pt-br/assuntos/insumos-agropecuarios/insumos-agricolas/sementes-e-mudas/publicacoes-sementes-emudas/INN44de23dedezembrode2010.pdf

Instrução Normativa $n^{\circ} 35$, de 14 de julho de 2011. (2011). Acrescenta ao caput do art. $1^{\circ}$ da Instrução Normativa $n^{\circ} 44$, de 23 de dezembro de 2010, algumas sementes de espécies florestais. https://redebiotecnologia.files.wordpress.com/2018/09/inm00000035.pdf

Instrução Normativa $n^{\circ} 34$, de 09 de setembro de 2014. (2014). Alteração da tabela que fixa os valores dos serviços públicos de que trata a Lei $\mathrm{n}^{\circ} 10.711$, de 5 de agosto de 2003, aprovada pelo art. $1^{\circ}$ da Instrução Normativa $\mathrm{n}^{\circ} 36$, de 28 de dezembro de 2004. http://www.abcsem.com.br/upload/arquivos/INSTRUCAONORMATIVAN34DE9DESETEMBRODE2014.pdf

Instrução Normativa $n^{o} 43$, de 15 de dezembro de 2015. (2015). Dispõe sobre a inscrição de espécies no Registro Nacional de Cultivares (RNC). https://www.legisweb.com.br/legislacao/?id=313801

Instrução Normativa $n^{\circ}$ 17, de 26 de abril de 2017. (2017). Regulamenta a Produção, a Comercialização e a Utilização de Sementes e Mudas de Espécies Florestais ou de Interesse Ambiental ou Medicinal, Nativas e Exóticas. https://www.gov.br/agricultura/pt-br/assuntos/insumos-agropecuarios/insumosagricolas/sementes-e-mudas/publicacoes-sementes-e-mudas/INN17de28042017comANEXOS.pdf

Instrução Normativa $n^{\circ}$ 19, de 16 de maio de 2017. (2017). Altera o parágrafo único do art. $1^{\circ}$ e o art. 56 da Instrução Normativa $\mathrm{n}^{\text {o }} 17$, de 2017. https://www.in.gov.br/materia/-/asset_publisher/Kujrw0TZC2Mb/content/id/20223673/do1-2017-05-19-instrucao-normativa-n-19-de-16-de-maio-de-201720223614

Lei $n^{o}$ 10.711, 5 de agosto de 2003. (2003). Dispõe sobre o Sistema Nacional de Sementes e Mudas e dá outras providências http://www.planalto.gov.br/ccivil_03/leis/2003/110.711.htm

MAPA, Ministério da Agricultura, Pecuária e Abastecimento. (2013). Instruções para análise de sementes de espécies florestais. https://www.gov.br/agricultura/pt-br/assuntos/laboratorios/arquivos-publicacoes-laboratorio/florestal_documento_pdf-ilovepdf-compressed.pdf

MAPA. Ministério da Agricultura, Pecuária e Abastecimentos. (2018). Plano Nacional de Desenvolvimento de Florestas Plantadas. https://www.gov.br/agricultura/pt-br/assuntos/politica-agricola/outras-publicacoes/plano-nacional-de-desenvolvimento-de-florestas-plantadas.pd

Oliveira, J. P. R., \& Ranal, M. A. (2014). Sementes florestais brasileiras: início precário, presente inebriante e o futuro, promissor?. Ciência Florestal, 24(3), 771-784. https://doi.org/10.1590/1980-509820142403024

Pereira, A. S., Shitsuka, D. M., Parreira, F. J., \& Shitsuka R. (2018). Metodologia de pesquisa científica. UFMS https://www.ufsm.br/app/uploads/sites/358/2019/02/Metodologia-da-Pesquisa-Cientifica_final.pdf

SNIF. Sistema Nacional de Informações Florestais. (2020). Espécies Florestais.: https://snif.florestal.gov.br/pt-br/especies-florestais 